\title{
Critical cerebral blood flow for production of hemiparesis after unilateral carotid occlusion in the gerbil
}

\author{
K. N A K A I, K. M. A. WE L C H, A N D J. S . MEYER \\ From the Baylor-Methodist Center for Cerebrovascular Research, and the Department of Neurology. \\ Baylor College of Medicine, Houston, Texas, USA
}

SUMMARY Transient cerebral ischaemia, produced by temporary unilateral common carotid artery (CCA) occlusion, was studied in the gerbil by means of chronically implanted hydrogen electrodes. Unilateral CCA occlusion produced behavioural signs of neurological deficit only when regional cerebral blood flow values in the ipsilateral cerebral hemisphere fell below a critical range of $0.20-0.22 \mathrm{ml} / \mathrm{gm}$ brain $/ \mathrm{min}$. Postischaemic poor perfusion (noreflow) was an infrequent observation after removal of CCA occlusion.

The gerbil is unique in its susceptibility to ipsilateral cerebral and ocular ischaemia after unilateral ligation of the common carotid artery (CCA) (Levine and Payan, 1966). Permanent bilateral carotid ligation is uniformly fatal to this species, and if transient bilateral occlusion is performed (Osburne and Halsey, 1975), the survival rate is also extremely low. This characteristic vulnerability to cerebral ischaemia induced by carotid occlusion is due to an inadequate collateral blood supply because of inefficient anastomoses between basilar and carotid arterial systems (Levine and Sohn, 1969; Levy and Brierley, 1974). Because of its small size and convenience, the gerbil has recently achieved popularity as an experimental stroke model, attested to by an increasing number of morphological and biochemical studies of brain ischaemia in this animal. So far, however, there have been only a small number of studies in which cerebral blood flow (CBF) has been measured in this model (Osburne and Halsey, 1975; Kelly and Halsey, 1976).

The purpose of the present series of experiments was to observe the effects of transient unilateral CCA occlusion on measurements of regional cerebral blood flow (rCBF) in the gerbil, and to determine the critical value for $\mathrm{rCBF}$ below which

This work was supported by Grant NS 09287 from the National Institute of Neurological and Communicative Disorders and Stroke, National Institutes of Health, Bethesda, Maryland.

Accepted 23 December 1976 neurological deficit and observations of ischaemia were consistently present. In addition, observations were made on the recovery of $\mathrm{rCBF}$ after removal of unilateral CCA occlusion. Levy et al. (1975) and Harrison et al. (1975), using techniques other than flow measurements, showed no evidence of postischaemic poor perfusion (no-reflow) after transient ischaemia in this model. Post-occlusive measurement of $\mathrm{rCBF}$ was, therefore, performed in the present experiments to confirm these observations. Finally, the haemodynamic and neurological findings after transient ischaemia and recirculation are discussed in relation to biochemical changes that have been reported elsewhere in the same experimental model (Gaudet et al., 1975).

\section{Materials and methods}

Thirty adult male and female Mongolian gerbils (Meriones unguiculatus) weighing from 37 to $64 \mathrm{gm}$ were studied. Animals were caged (three per unit) at constant temperature in simulated day and night conditions and allowed free access to drinking water and chow. Under pentobarbital anaesthesia $(50 \mathrm{mg} / \mathrm{kg})$, platinised-platinum open tip electrodes, $0.3 \mathrm{~mm}$ in length and $100 \mu \mathrm{m}$ in diameter, were implanted through the skull in the region of both external borders of the orbital ridge. This area was chosen for implantation since the electrodes were placed in the cerebral cortex 
lateral to the hippocampus, where the region of ischaemic changes has been shown to be the most extensive (Kahn, 1972). The open-tip electrodes were implanted three to six days before the experiments to ensure consistent responses to hydrogen inhalation (Meyer et al., 1972).

On the day of the experiment, the previously prepared gerbils were lightly anaesthetised with ether, and spontaneous respiration was maintained throughout. If respiratory difficulty or arrest occurred these animals were discarded. The use of ether anaesthesia was advantageous because the gerbils became alert and responsive promptly after termination of ether inhalation, and clinical signs of ischaemia could be evaluated at an early stage. These signs included ipsilateral rotation, ipsilateral ptosis, contralateral hemiparesis, and, in some cases, rolling fits.

Through a ventral midline cervical incision, either the left or right common carotid artery was exposed with the aid of a stereoscopic microscope. The vagus nerve and the jugular vein were carefully separated. Tracheal intubation was then performed using a PE 90 tube. A subcutaneous $\mathrm{Ag}-\mathrm{AgCl}$ electrode was then placed in the neck muscles, and rCBF was measured by the hydrogen inhalation method (Meyer et al., 1972).

The rCBF was calculated by compartmental analysis using the formula:

$$
F=\lambda 0.693 / \mathrm{t}(1 / 2) \mathrm{ml} / \mathrm{gm} \text { brain } / \mathrm{min}
$$

where $\lambda$ is the blood : brain partition coefficient for hydrogen. The first one minute portion of the desaturation curve for hydrogen was excluded to avoid contamination due to recirculation.

The study was conducted according to the following protocol. Steady state measurements of rCBF were made. The right or left carotid artery was then occluded for 30 minutes using a miniaturised Mayfield clip, and rCBF measurements were repeated during this ischaemic period. In 12 animals these measurements were made at two separate intervals during the 30 minutes of ischaemia. Further measurements were repeated 30 minutes after removal of the carotid clip (postocclusion period).

Cerebral necropsy was performed in all animals. Confirmation of electrode placement was done macroscopically after sectioning of the formalin fixed brain. If the electrode placement was unsatisfactory, this animal was discarded from the experiment.

Student's $t$ test was used for statistical comparison of significant differences in the means. Significant differences were considered to be present with a $5 \%$ level of confidence or better.

\section{Results}

Upon recovery from the ether anaesthesia, 18 gerbils $(60 \%)$ exhibited clinical signs of ischaemia (symptomatic group). These signs persisted throughout the period of occlusion and resolved spontaneously within 60 minutes after removal of occlusion. No ischaemic signs were detected in the remaining 12 animals (asymptomatic group).

Figure 1 shows individual rCBF values in the occluded hemisphere of asymptomatic and symptomatic animals. Flow values fell into two clear groups. Below a rCBF range of $0.20-0.22 \mathrm{ml} / \mathrm{gm}$ brain $/ \mathrm{min}$, all animals showed signs of ischaemia, but signs of ischaemia were not observed with flow values above this range. The mean rCBF value for all animals studied during a steady state period was $0.42 \pm 0.10 \mathrm{ml} / \mathrm{gm}$ brain/ min. No significant difference was observed in rCBF between the symptomatic $0.40 \pm 0.07 \mathrm{ml} / \mathrm{gm}$ brain $/ \mathrm{min})$ and the asymptomatic $(0.45 \pm 0.08 \mathrm{ml} /$ $\mathrm{gm}$ brain $/ \mathrm{min}$ ) groups. During unilateral carotid artery occlusion, the mean $\mathrm{rCBF}$ value in the hemisphere ipsilateral to the occlusion significantly decreased from steady state to $0.11 \pm 0.07$ $\mathrm{ml} / \mathrm{gm}$ brain $/ \mathrm{min}$ ) in the symptomatic group and $0.33 \pm 0.06 \mathrm{ml} / \mathrm{gm}$ brain $/ \mathrm{min}$ in the asymptomatic group, the mean values also being significantly different between groups (Fig. 2). The rCBF was measured twice in 12 animals during 30 minutes of ischaemia. No significant difference was observed between the mean values of the first and second measurements. In the post-occlusion period, rCBF values did not differ from steady state values, the mean $\mathrm{rCBF}$ being $0.46 \pm 0.10 \mathrm{ml} / \mathrm{gm}$ brain/min in the asymptomatic group, and $0.35 \pm 0.11 \mathrm{ml} / \mathrm{gm}$ brain $/ \mathrm{min}$ in the symptomatic group. However, the difference between postocclusion mean values in the two groups was significant (Fig. 2).

Values for rCBF in the hemisphere contralateral to the occluded carotid artery were not significantly different from steady state during the occlusion and post-occlusion periods in animals both symptomatic and asymptomatic of ischaemia (Fig. 3).

\section{Discussion}

BEHAVIOURAL OBSERVATIONS AFTER UNILATERAL CAROTID OCCLUSION

Clinical signs of cerebral ischaemia occurred after unilateral CCA occlusion in $60 \%$ of animals. This incidence rate was marginally higher than has been reported previously from this and other labora- 


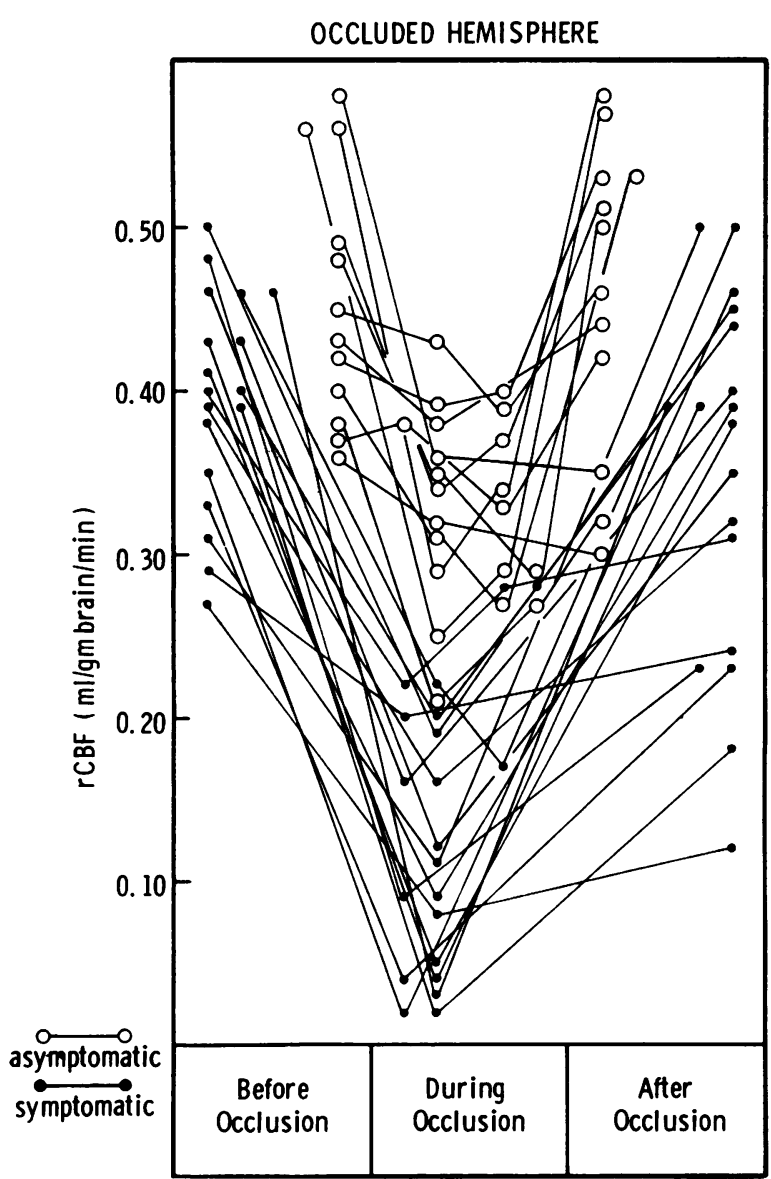

OCCLUDED HEMISPHERE

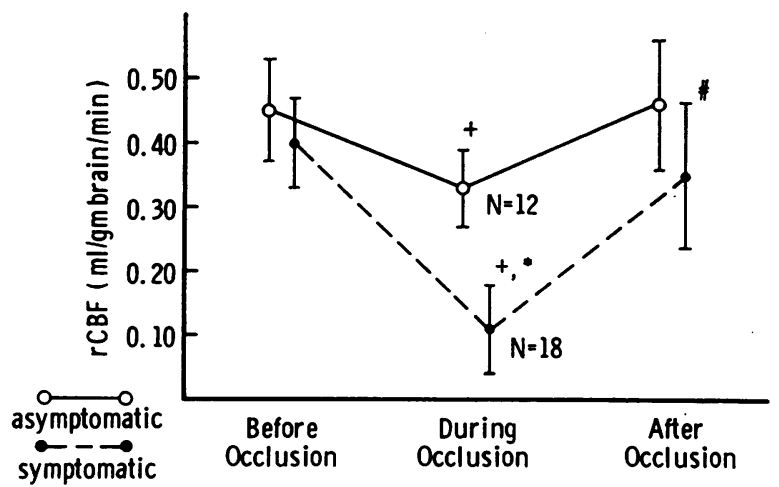

Fig. 1 Individual $r C B F$ values in the ipsilateral hemisphere before, during, and after unilateral common carotid artery occlusion in the gerbil. Note that no striking alteration in $\mathrm{rCBF}$ values takes place in those animals in which $\mathrm{rCBF}$ is measured twice during occlusion. Note also that all animals with $\mathrm{rCBF}$ values below a range of $0.20-0.22 \mathrm{ml} / \mathrm{gm} \mathrm{brain} / \mathrm{min}$ became symptomatic of ischaemia.

Fig. 2 Significant reduction of mean $r C B F$ values in the ipsilateral hemisphere of animals both symptomatic and asymptomatic of ischaemia after unilateral common carotid artery occlusion. Reduction of rCBF is greater in animals symptomatic of ischaemia. $+=$ significantly different from steady state, $P<0.001$,

*=significantly different from asymptomatic animals, $P<0.001, \#=$ significantly different from asymptomatic animals, $P<0.01$. 
CONTRALATERAL HEMISPHERE

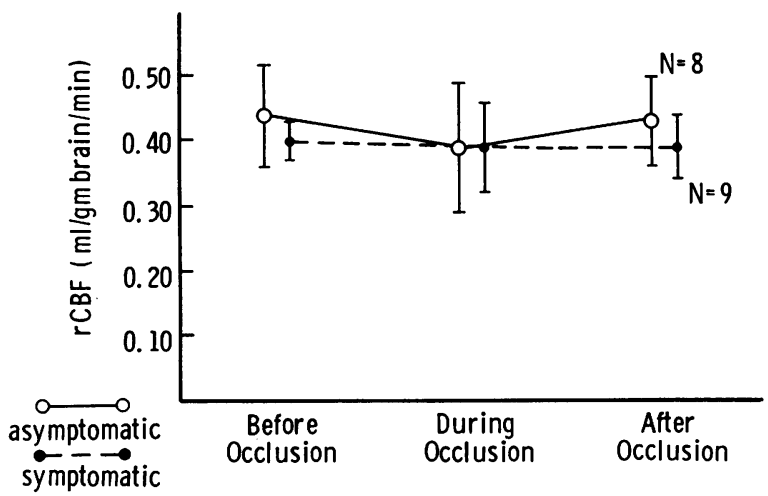

Fig. 3 No significant change in mean $r C B F$ values of the contralateral hemisphere during or after unilateral common carotid artery occlusion in animals both symptomatic and asymptomatic of ischaemia. tories but compares well with an early report by Harrison et al. (1973). Some batch variability has been noted in previous studies, and large numbers of animals must be studied if a valid incidence rate is to be assessed, which in larger series of experiments was consistently 40-50\% (Welch et al., 1977).

CORTICAL BLOOD FLOW IN THE GERBIL

The measurement of the steady state values for cortical rCBF in these experiments was lower than that previously reported using a similar technique (Osburne and Halsey, 1975). Since there was also much greater variability in individual flow values in the quoted study, the differences in mean values are probably accounted for by differences in experimental techniques and anaesthetic procedures used.

During CCA occlusion, the rCBF values in the ipsilateral side of the symptomatic group were significantly lower than those measured in the asymptomatic group. There was a clear-cut critical rCBF below which ischaemic signs were produced. The rCBF in the cerebral hemisphere ipsilateral to the side of occlusion became critically reduced within minutes of applying the clip to the carotid artery. The fact that flow remained reduced without recovery in the 12 animals in which two measurements were made during occlusion indicates that collateral circulation is extremely inefficient in this species, as would be predicted from anatomical observations of the carotid and vertebro-basilar systems at the base of the brain (Levine and Payan, 1966; Levy and Brierley, 1974).

Upon removal of CCA occlusion, flow values returned to pre-occlusion values; in only four of 18 animals was there any failure of re-perfusion, which probably accounts for the small difference in post-occlusion values between symptomatic and asymptomatic groups. The studies of Levy et al. (1975) and Harrison et al. (1975) have also indicated that impaired re-perfusion (no-reflow) is uncommon in this experimental model.

In a preliminary series of experiments, gerbils were implanted with oxygen electrodes in the same area of the hippocampus. It was observed that, immediately after clipping the ipsilateral carotid artery, the tissue $\mathrm{pO}_{2}$ in this area dropped precipitously and rose rapidly immediately after the clip was released. In six symptomatic animals the reduction of tissue $\mathrm{pO}_{2}$ was greater than in two animals without neurological deficit, and the $\mathrm{pO}_{2}$ values did not always return to pre-occlusion values. Failure of tissue $\mathrm{pO}_{2}$ levels to return to steady state was a more frequent observation. This would appear to be in accord with the histological findings of Levy et al. (1975) who saw evidence of cortical neuronal damage despite reperfusion of tissue. Further studies are under way to examine the critical tissue $\mathrm{pO}_{2}$ at which neuronal damage takes place. The evidence of dissociation between flow and tissue $\mathrm{pO}_{2}$ after transient ischaemia seems to indicate that tissue $\mathrm{pO}_{2}$ is more critical to continued metabolic dysfunction and neuronal damage, and persistent reduction of tissue $\mathrm{pO}_{2}$ is not necessarily associated with impaired reperfusion.

Rotational behaviour in a direction ipsilateral to that of the occluded carotid artery, recognised as a behavioural concomitant of dopaminergic stimulation of the ipsilateral striato-nigral system (Costall and Naylor, 1975), was observed as part of the symptom complex that indicates the successful induction of ischaemia in the gerbil model. Rapid unilateral release and depletion of dopamine (DA) was confirmed in the occluded hemis- 
phere of symptomatic gerbils immediately after unilateral CCA occlusion (Gaudet et al., 1975). Such a depletion was not seen in asymptomatic animals. In the present experiments neuronal DA release and depletion took place only when rCBF fell below the critical level of $0.22 \mathrm{ml} / \mathrm{gm}$ brain/ min. Since ischaemia inevitably progressed in this group of animals, DA may play some role in this process.

The observation that $\mathrm{rCBF}$ decreases in occluded hemispheres of asymptomatic as well as symptomatic animals is in keeping with observed biochemical changes in this animal group (Gaudet et al., 1975). Comparative study of biochemical changes in asymptomatic and symptomatic animals could prove fruitful in an understanding of the metabolic as well as the haemodynamic mechanisms contributing to the progression or resolution of ischaemia. It is suggested that the gerbil is an ideal model in which to pursue such studies.

\section{References}

Costall, B., and Naylor, R. J. (1975). A comparison of circulating mcdels for the detection of antiparkinson activity. Psychopharmacologia, 41, 57-64.

Gaudet, R., Chabi, E., Welch, K. M. A., and Wang, B. (1975). Effect of transient ischemia on moncamine levels in the cerebral cortex of gerbils. In Neuroscience Abstracts, 5th Annual Meeting, Vol. 1, p. 397. Society for Neuroscience: Bethesda, Maryland.

Harrison, M. J. G., Brownbill, D., Lewis, P. D., and Ross Russell, R. W. (1973). Cerebral edema following carotid artery ligation in the gerbil. Archives of Neurology (Chicago), 28, 389-391.

Harrison, M. J. G., Sedal, L., Arnold, J., and Ross Russell, R. W. (1975). No-reflow phenomenon in the cerebral circulation of the gerbil. Journal of Neurology, Neurosurgery, and Psychiatry, 38, 11901193.

Kahn, K. (1972). The natural course of experimental cerebral infarction in the gerbil. Neurology (Minneapolis) 22, 510-515.

Kelly, R. A., and Halsey, J. H. (1976). Comparison of local blood flow and oxygen availability at the same locus in the ischemic gerbil brain. Stroke, 7, 274278.

Levine, S., and Payan, H. (1966). Effects of ischemia and other procedures on the brain and retina of the gerbil (Meriones unguiculatus). Experimental Neurology, 16, 255-262.

Levine, S., and Sohn, D. (1969). Cerebral ischemia in infant and adult gerbils. Archives of Pathology, 87, 315-317.

Levy, D. E., and Brierley, J. S. (1974). Communications between vertebro-basilar and carotid arterial circulations in the gerbil. Experimental Neurology, 45, 503-508.

Levy, D. E., Brierley, J. B., and Plum, F. (1975). Ischaemic brain damage in the gerbil in the absence of 'no-reflow'. Journal of Neurology, Neurosurgery, and Psychiatry, 38, 1197-1205.

Meyer, J. S., Fukuuchi, Y., Kanda, T., Shimazu, K., and Hashi, K. (1972). Regional cerebral blocd flow measured by intracarotid injection of hydrogen. Comparison of impaired regional vasomotor capacitance from cerebral infarction versus compression. Neurology (Minneapolis), 22, 571-584.

Osburne, R. C., and Halsey, J. H. (1975). Cerebral blood flow. Archives of Neurology (Chicago), 32, 457-461.

Welch, K. M. A., Chabi, E., Buckingham, J., Bergin. B., Achar, V. S., and Meyer, J. S. (1977). Catecholamine and 5-hydroxytryptamine levels in ischemic brain. Influence of p-chlorophenylalanine. Stroke. In press. 